\title{
Time Punctuality and Economic Performance
}

\author{
William Di Pietro \\ Business Department, Daemen College \\ 4380 Main St., Amherst, NY 14226, USA \\ Tel: 1-716-839-8427 E-mail: wdipietr@daemen.edu
}

Received: January 17, 2014 Accepted: February 24, 2014 Published: March 4, 2014

doi:10.5296/jsss.v1i2.5232 URL: http://dx.doi.org/10.5296/jsss.v1i2.5232

\begin{abstract}
This paper employs cross country regression analysis on an index of time punctuality to see whether or not an important cultural trait, time punctuality, influences economic development and other economic performance variables. The results are consistent with the idea that punctuality matters for economic development, and for country innovation, country competitiveness, and the effectiveness of a country's government. Punctuality is statistically pertinent as an explanatory variable for country performance variables whether it is used singularly on its own in regressions, or in combination with the level of economic development.
\end{abstract}

Keywords: Time punctuality, Economic performance, Culture, Innovation, Economic development 


\section{Introduction}

Culture is one potential reason ( perhaps, among economists, a rather overlooked reason) for differences in the levels of economic development and for differential economic performance of countries around the world. An especially important cultural dimension with regard to its possible impact on production and economic activity is time punctuality, or time consciousness.

It is probably no accident that Europeans were the first to develop the mechanical clock, and, at the same time, to develop economically. Good time keeping allows one to monitor efficiency, which is measured in terms of output per unit of time, and, thereby, to establish more efficient techniques and practices, and, generally, to become more efficient conscious. It allows for precision, good measurement, and the advancement of science. It is only in time conscious societies that one gets the notion that time is money; with the result that time is considered scarce, always taken into consideration, and used only with much care, diligence, and planning.

The study considers two interconnected hypothesis. The first is that time punctuality is a positive force for economic development of a nation, and the lack of time consciousness an impediment to economic development. The second is that key economic performance variables such as innovation and national competitiveness are both directly positively influenced by time punctuality, and indirectly positively affected by time punctuality by its effect on economic development. In other words, time consciousness is expected to have a positive effect on economic development, and, in turn, economic development and time consciousness are predicted to have a positive effect on economic performance.

Three economic performance dimensions are considered. They are innovation, competitiveness, and effectiveness of government. Innovation and competitiveness are predicted to be positively related to time punctuality, while ineffectiveness in government is considered to be negatively related to time punctuality.

The paper is divided into six additional sections. Section two reviews a bit of the literature. The following section presents a simple model explaining how time punctuality affects development and other economic performance variables. The fourth section identifies the variables to be used in the empirical section and their sources. The fifth shows the results of cross country regressions of economic development and of economic performance variables on punctuality, and of regressions of economic performance variables on both punctuality and the level of economic development. The sixth section concludes. The seventh and final section adds a short postscript.

\section{Literature Review}

Hezel puts forth the case that the typical conditions for economic development suggested by main stream economists (access to capital and technology, favorable circumstances for investment, stable and dependable government and institutions) are necessary but not sufficient conditions for economic development (Hazel, 2009). In addition to these, development requires the presence of a constellation of cultural traits and attitudes in a people within a country such as trust in others, generalized morality, and an ethic of hard work.

In his book, The Wealth and Poverty of Nations, Landes addresses the question of why some 
countries are poor and some countries are rich, and why some countries move from being poor to rich while other countries do not, by looking historically at Europe and at individual countries throughout the world (Landes, 1999). He concludes that the existences of certain cultural characteristics are critical for a country to make the transition from poor to rich. For instance, he believes that countries with people who live to work are much more likely to succeed in undertaking the difficult process of economic development than countries with people who work to live. In his view, Japan's strong work ethic is the key to its being the first country in the East to modernize and become wealthy.

Tabellini empirically investigates whether cultural factors have a causal effect on economic development (Tabellini, 2010). Using a sample of sixty-nine regions in eight European countries and employing instrumental variables estimation, he finds that four cultural variables, trust in others, respect for others, the sense of individual control, and obedience, matter for economic development, with the first three positively correlated to development, and the last negatively correlated to development.

After giving a quick review of the debate on the relationship between culture and economic outcomes starting with the Classical economists, Guiso, Sapienza, and Zingales empirically look at a few cultural variables in order to see whether culture affects economic outcomes (Guiso, Sapienza, \& Zingales 2006). As they are very concerned with the possibility that the causality between economic outcomes and cultural outcomes might go in both directions, in their analysis, they employ instrumental variables when estimating the effect of culture on economic outcomes. Three of the main empirical findings of their article are, first, that ethnicity and religion affects trust and that trust in turn is an important factor for becoming an entrepreneur, second, that religious affiliation affects preferences for savings and savings preferences in their turn affect actual savings, and, third, that religious affiliation affects peoples preferences for government involvement in redistribution and that these preferences affect actual government redistribution policies.

Dodor and Rana look at the potential effect of Hofstede's five cultural variables, power distance, uncertainty avoidance, individualism, masculinity/femininity, and long-term orientation on development and on allocative resource efficiency (Dodor \& Rana, 2007). Their results indicate that three of the five cultural variables, power distance, uncertainty avoidance, and individualism are statistically relevant for both development and for allocative efficiency.

Under the understanding that the existing trust within a country depends on its current environment and on its inherited trust from previous generations, Algan and Cahuc make use of the inherited trust of U.S. immigrants, and, in their empirics, employing a panel of countries for two periods, 1935-1938 and 2000-2003, they find evidence in support of the notion that economic development depends causally on trust (Algan \& Cahuc, 2008).

Using a panel consisting of 141 countries from 1970 to 2004, Williamson and Matters look at the effect of freedom and other cultural variables, trust, self-determination, respect for others, and obedience, on economic growth (Williamson \& Matters, 2011). They find that, although freedom seems to be more important for economic growth than other cultural factors, culture still seems to matter for economic growth. 
Gorodnichenko and Roland look at a large number of different cultural variables employing survey data from three different sources (Gorodnichenko \& Roland, 2011). Their regression analysis shows that individualism is robustly associated with long run economic growth.

In their growth regressions on twenty nine countries, Forson, Janrattanagul and Carsamer find that cultural variables add to the explanation of economic growth when added to traditional economic variables (Forson, Janrattanagul, \& Carsamer, 2013). Their results indicate that traditional rationality, behavior based on tradition, has a statistically negative effect on economic growth.

Osoba focuses on the relationship between entrepreneurial activity and cultural variables (Osoba 2009). Using panel data for U.S. States for the years 1998 to 2003, his empirics suggests that uncertainty avoidance, masculinity, and long-term orientation are three possible cultural variables that may matter for entrepreneurial activity.

Petrakis proposes that the difference in economic performance between Northern European and Southern European countries may be due to differences in culture (Petrakis, 2011). He finds that Northern European countries score high on Individualism, but that , Southern European countries tend to have high uncertainty avoidance and to lack future orientation.

Looking back historically, F.W. Maitland saw the English legal creation of the trust, in its inception literally based on trust in others, by mitigating the power of the central government from eliminating private associations of groups, as fundamental to the very emergence of modern pluralistic, democratic society (Macfarlane, 2002).

\section{A Time Punctuality Model of Economic Development and Economic Performance}

The model consists of a set of two equations. The first equation, Equation 1, is the relationship between economic development and punctuality. In Equation 1, D stands for the level of economic

$$
\mathrm{D}=\mathrm{f}(\mathrm{T}) \quad \mathrm{dD} / \mathrm{dT}>0
$$

development and $\mathrm{T}$ represents time punctuality. As indicated by development's derivative with regard to time, economic development is expected to be positively related to time punctuality, with greater time punctuality leading to higher economic development, and reduced time punctuality to lower levels of economic development.

The second equation shows a generalized equation for an economic performance variable that is

$$
\mathrm{P}=\mathrm{f}(\mathrm{T}, \mathrm{D}) \quad \delta \mathrm{P} / \delta \mathrm{T}>0, \delta \mathrm{P} / \delta \mathrm{D}>0
$$

favorable to the economy. In the equation, $\mathrm{P}$ represents economic performance that is favorable to the economy, with the other letters are defined in the same way as they are in the first equation. The performance of an economic variable that is favorable for the economy is predicted to be positively related to both time punctuality and the level of economic development, while the performance of an economic variable that is unfavorable for the economy is predicted to be negatively related to time punctuality and the level of economic development.

Thus, in the model, punctuality is anticipated to have a positive effect on economic development. Time punctuality is also expected to have a double positive impact on a 
performance variable favorable to the economy (double negative effect on a performance variable that is unfavorable to the economy such as government ineffectiveness) that works through two channels. The first, considering $\mathrm{T}$ in Equation 2, is its direct effect on a performance variable, and the second, looking at $\mathrm{T}$ in Equation 1 and $\mathrm{D}$ in Equation 2, is its indirect effect working through its effect on development.

Three economic performance variables will be considered. They are innovation, competitiveness, and government ineffectiveness.

\section{The Variables and Their Data Sources}

Culture Crossing is an internet site that provides cultural information for travelers and others for different countries (Culture Crossing, 2013). One of its categories is called views of time. Within this category, site contributors generally discuss whether people are punctual or laid-back, whether buses and public transportation typically arrive on time, and whether people are generally expected to be tardy or punctual for business and social engagements. Using the Cross Culture country descriptions for the views of time category, an index of time punctuality is constructed by the author by ranking countries form one to four, assigning higher values to countries with greater time punctuality and lower values to countries with lesser time regard, or smaller time consciousness.

A quick look at the regional pattern of the punctuality index is very consistent with the notion that the lack of punctuality, the absence of time consciousness, is an obstacle to economic development. The developed countries, Western Europe, Japan, and the United States score very highly on the punctuality index. African and South American countries typically have very low values.

A common measure of economic development is GDP per capita. Here, the level of economic development is captured by per capita real GDP for the year 2005 in 2000 dollars. The data come from the World Bank (World Bank, 2011).

The 2009 global innovation index of the Confederation of Indian Industry and INSTEAD is employed to measure innovation (Confederation of Indian Industry and INSTEAD, 2010). The index is available for one hundred and thirty countries and ranges in value from one to seven with higher values indicating greater innovation.

The 2007 Global competitiveness index of the World Economic Forum is employed to quantify competitiveness (World Economic Forum, 2007). Higher values of the competitiveness index indicate greater competitiveness. In 2007, the index ranged from a low value of 2.78 for Chad to a high value of 5.67 for the United States.

The measure of government ineffectiveness is the 2010 failed states index of the Fund for Peace (Fund for Peace, 2011). The index ranges from twelve to one hundred twenty with higher values indicating poorer state performance. The index is available for one hundred seventy seven countries in 2010 .

Average years of schooling of adults twenty five years of age and over for 2000 are used to proxy human capital. Data on average years of schooling is available for various years from statistics provided by the United Nations (United Nations, 2013).

\section{Cross Country Empirical Results}

Table I shows the results of simple cross country regressions using ordinary least squares of 
the measures of economic development, innovation, competitiveness, and state failure on the index of time punctuality.

Table 1. Simple cross country regressions of economic development, innovation, competitiveness, and state failure on time punctuality

\begin{tabular}{lllll}
\hline & $(1)$ & $(2)$ & $(3)$ & $(4)$ \\
\hline \multirow{4}{*}{ Constant } & Development & Innovation & Competitiveness & State Failure \\
& -11395.31 & 1.81 & 2.78 & 111.31 \\
& $(-5.83)$ & $(13.78)$ & $(20.41)$ & $(24.83)$ \\
& $*$ & $*$ & $*$ & $*$ \\
Punctuality & 8873.24 & .6243 & .6196 & -19.34 \\
& $(10.13)$ & $(11.39)$ & $(10.92)$ & $(-9.91)$ \\
& $*$ & $*$ & $*$ & $*$ \\
$\mathrm{NSQ}$ & .432 & .548 & .525 & .421 \\
\hline
\end{tabular}

The table is set up with the first column listing the potential explanatory variables. These are followed by the r-squared value (RSQ) and the number of countries entering an equation (N). Subsequent columns give the results for individual regression runs, one per column. These are numbered in the first row, with the second row identifying the dependent variable used for an equation. The entries in the body of the table show the estimated coefficients for the explanatory variables in the equations. Their individual t-statistics are underneath in parenthesis. Lastly, when a variable is significant at the one percent level or better in an equation, then a single asterisk appears underneath the individual t-statistic.

The results lend support to the hypothesis that time punctuality matters for overall economic development, and for economic performance in terms of innovation, competitiveness, and the extent of state failure. Punctuality has the theoretically expected sign in all the equations, positive with regard to development, innovation, and competitiveness, and negative with regard to state failure. Its estimated coefficient is significant at the one percent level or better in all four equations. Time punctuality as the sole explanatory variable explains over forty two percent of the cross country variation in each of the four different dependent variables.

The quantitative impact of punctuality on the variables also appears to be of some consequence. For example, looking at the estimated coefficient of punctuality in the first equation shows that a single point gain in the index of time punctuality, which can vary between one and four, leads to an increase in per capita GDP by close to nine thousand dollars.

Table II adds a measure of human capital, average years of schooling, as an additional independent variable to punctuality to explain economic development, and adds economic development to punctuality, as an additional explanatory variable to explain the economic 
performance variables of innovation, competitiveness, and state failure. In addition to assessing the first hypothesis of the paper, whether punctuality is important for economic development and for the performance variables that was possible with Table 1, Table 2 allows us also to evaluate the second hypothesis of the paper, whether punctuality has a direct and an indirect effect on investment, competitiveness, and state failure.

Table 2. Cross country multiple regressions of economic development on time punctuality adjusting for the extent of human capital; and of innovation, competitiveness, and state failure on time punctuality adjusting for the level of economic development

\begin{tabular}{|c|c|c|c|c|}
\hline & (1) & (2) & (3) & (4) \\
\hline & Development & Innovation & Competitiveness & State Failure \\
\hline \multirow[t]{3}{*}{ Constant } & -18089.56 & 2.41 & 3.24 & 95.71 \\
\hline & $(-8.54)$ & $(26.61)$ & $(26.42)$ & $(26.62)$ \\
\hline & $*$ & $*$ & $*$ & $*$ \\
\hline \multirow[t]{3}{*}{ Punctuality } & 7269.80 & .1898 & .2871 & -8.27 \\
\hline & $(6.22)$ & $(4.14)$ & $(4.70)$ & $(-4.30)$ \\
\hline & $*$ & $*$ & $*$ & $*$ \\
\hline \multirow[t]{3}{*}{ Development } & & .000048 & .000035 & -.0013 \\
\hline & & $(13.71)$ & $(8.10)$ & $(-8.91)$ \\
\hline & & $*$ & $*$ & $*$ \\
\hline \multirow[t]{3}{*}{ Avgschooling } & 1516.08 & & & \\
\hline & $(4.35)$ & & & \\
\hline & $*$ & & & \\
\hline RSQ & .683 & .837 & .711 & .667 \\
\hline $\mathrm{N}$ & 115 & 109 & 93 & 132 \\
\hline
\end{tabular}

Looking at the first equation of Table 2 shows that punctuality matters for economic development even after adjusting for the effect of human capital. The estimated coefficient on punctuality is positive and significant at the one percent level or better in Equation (1). The human capital variable also behaves nicely. It is highly significant and its estimated effect on development is positive.

Equations (2) through (4) of table II show that both punctuality and economic development matter for each of the three economic performance variables. Both punctuality and development are positive and significant at the one percent level of significance or better in these equations. This means, given the positive effect of punctuality on economic development suggested by equation one, that punctuality has double effect on the three economic performance variables, a direct effect, and an indirect effect working through its effect on economic development. 


\section{Conclusion}

Some cultural traits are likely to enhance development and economic performance, while other cultural traits may diminish development and economic performance. If a country possesses a sufficient number of cultural traits that negatively impact development in a quantitatively substantial fashion, it may be impossible for that country to have long term sustained economic development without a major cultural shift involving the removal of old well entrenched negative cultural developmental features and the nurturing and replacement with new positive ones. This may still be the case even under the most favorable economic circumstances for economic development for a country. That is to say, culture may be a major obstacle to development that cannot be overcome by other positive conditions in a country.

This paper finds, using cross country regression analysis, that one important positive cultural characteristic for development is time punctuality. Countries that value a slow pace, a leisurely lifestyle, need to be aware of the real possibility that keeping this (in and of itself desirable) culture characteristic may slow their rate of economic development, or reduce their chances of sustained development, or even preclude their long-term development. The results of the paper indicate that the lack of time punctuality has a negative effect on economic development and on critical important economic performance variables such as innovation, competitiveness, and effective state functioning.

\section{Postscript}

Not only is it important whether culture matters for economic development, but the way in which development is affected by culture matters. Some in their enthusiasm to promote Multi-Culturalism take the position that development can be adapted to any culture, and, in so doing, may inadvertently be doing a disservice to developing countries chances for development, when it is the case that certain cultural characteristics are harmful for economic development. When certain cultural traits are negative for economic development, or, at the very extreme, represent insurmountable obstacles to development, then these cultural traits cannot be allowed to persist without damaging economic development.

Culture for many nations is part of their national identity. The preservation of their culture is considered to be sacrosanct. However, these nations also strongly desire economic development. They want to preserve their culture, but at the same time, achieve economic development. While for certain cultural aspects this may be possible, for others it may be a difficult, if not, an impossible task. Nations operate under a mistaken notion when they believe negative cultural traits can be preserved without hindering economic development.

Economists generally maintain that more goods are better than fewer goods. This means that social welfare is enhanced by producing a greater quantity of goods. The position implicitly assumes ceteris paribus or all other things being the same. However, the production of more goods through economic development is sure to entail major cultural changes. If the pre-economic development cultural conditions are valued more highly than the post-economic development cultural milieu, then the cultural changes necessary for greater economic development and production is a cost that must be bore for higher production and economic development, a real cost that reduces the potential welfare gains of greater output of goods. 
With regard to time considerations, economic development is likely to require the sacrifice of investment of time and energy in personal relationships for greater time punctuality. Countries that place little weight on being on time generally place great value on relationships and personal relationships development, that is, with spending time with people. Unfortunately, this means, for these countries, that if time punctuality really matters for economic development, as indicated by the findings in this paper, something of real value, personal relationships, may have to be sacrificed for sustained economic development.

\section{References}

Algan, Yann, \& Pierre Cahuc. (2008). Cultural Change and Economic Development. Retrieved from http://econ.sciences-po.fr/sites/default/files/algan/EcoDev.pdf

Confederation of Indian Industry and INSTEAD. Global innovation Index. 2010. Retrieved from http://www.globalinnovationindex.org/gii/main/home.cfm

Culture Crossing, A Community Built Guide to Cross-Cultural Etiquette and Understanding, Retrieved from http://www.culturecrossing.net/index.php

Dodor, J., Baptiste K., \& Dharan, S. R. (2007). Culture and Economic Development: An Investigation using Hofstede Cultural Dimensions. International Journal of Business Research, 7(2), 75-84.

Foreign Policy. (2012). The Failed State Index for 2010. Retrieved from http://www.fundforpeace.org/global/?q=fsigrid2010

Forson, J. Ato, Jakkaphong, J., \& Emmanuel, C. (2013). Culture Matters: A test of Rationality on Economic Growth. Asian Social Science, 9(9), 287-300. http://dx.doi.org/10.5539/ass.v9n9p287

Gorodnichenko, Y., \& Roland, G. R. (2011). Which Dimensions of Culture Matter for Long-Run Growth? American Economic Review: Papers \& Proceedings, 101(3), 492-498. http://dx.doi.org/10.1257/aer.101.3.492

Guiso, L., Paola, S., \& Luigi, Z. (2006). Does Culture Affect Economic Outcomes? The Journal of Economic Perspectives, 20(2), 23-48. http://dx.doi.org/10.1257/jep.20.2.23

Hezel, Francis, X., S. J. (2009). The Role of Culture in Economic Development. Micronesian Counselor, 77, 1-19. $\quad$ Retrieved from http://www.micsem.org/pubs/counselor/frames/culture_economic_developmentfr.htm Landes, D. S. (1999). The Wealth and Poverty of Nations. New York: W. W. Norton \& Company.

Macfarlane, A. (2002). F.W. Maitland and the Making of the Modern World. Cambridge: Palgrave. Retrieved from http://www.alanmacfarlane.com/TEXTS/Maitland_final.pdf

Osoba, B. J. (2009). Culture and Entrepreneurial Activity in the United States: A Quantitative Analysis. The European Journal of Social Science Research, 22(3). 341-370. http://dx.doi.org/10.1080/13511610903367820

Petrakis, P. E. (2011). Cultural Background and Economic Development Indicators: European South Vs European North. Modern Economy, 2, 324-334. http://dx.doi.org/10.4236/me.2011.23035

Tabellini, G. (2010). Culture and Institutions: Economic Development in the Regions of 


\section{Macrothink}

Journal of Social Science Studies

ISSN 2329-9150 2014, Vol. 1, No. 2

Europe. Journal of European Economic Association, 8(4), 677-716. http://dx.doi.org/10.1111/j.1542-4774.2010.tb00537.x

The Fund for Peace. (2011). The Failed States Index Report for 2010, The Fund for Peace Publications. Retrieved from http://www.fundforpeace.org/global/library/cr-10-99-fs-failedstatesindex2010-1103g.pdf

The Global Competitiveness Report (2007-2008). Retrieved from http://www.immi-to-australia.com/pics/advant/2007_WorldEconomicForum.pdf

United Nations. (2013). 2013 Human Development Report, International Human Development Indicators. Retrieved from http://hdrstats.undp.org/en/indicators/103006.html Williamson, Claudia R., \& Rachel, L. M. (2011). Economic freedom, culture, and Growth. Public Choice, 148(3-4), 313-335. http://dx.doi.org/10.1007/s11127-010-9656-z

World Bank. (2011). World Development Indicators. http://data.worldbank.org/indicator

\section{Copyright Disclaimer}

Copyright reserved by the author(s).

This article is an open-access article distributed under the terms and conditions of the Creative Commons Attribution license (http://creativecommons.org/licenses/by/3.0/). 